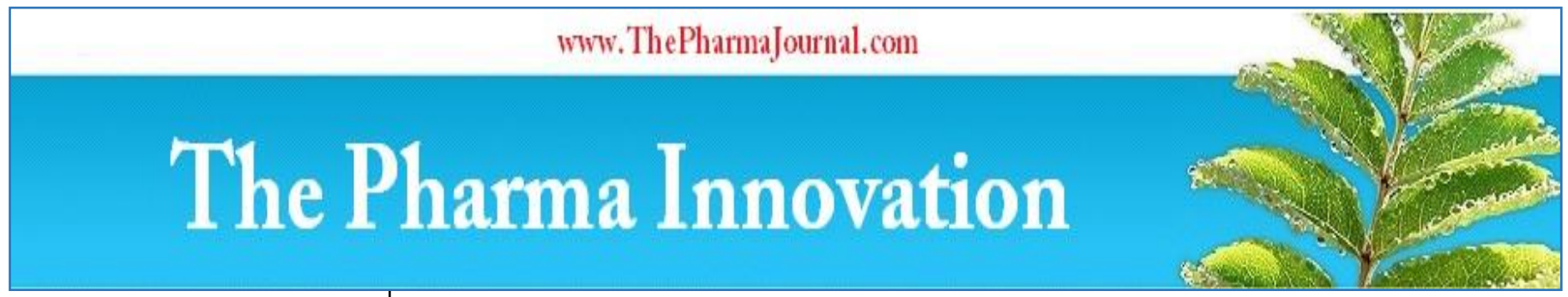

ISSN (E): 2277 - 7695

ISSN (P): 2349-8242

NAAS Rating: 5.23

TPI 2021; 10(4): 653-657

(C) $2021 \mathrm{TPI}$

www.thepharmajournal.com

Received: 04-02-2021

Accepted: 06-03-2021

Tripathi Dipti

P.G. Scholar, Department of

Food and Nutrition, Faculty of

Home Science, Bindheswari P.G.

College, Akbarpur,

Uttar Pradesh, India

Yadav Latika

Assistant Professor,

Department of Food and

Nutrition, Faculty of Home

Science, Bindheswari P.G.

College, Akbarpur,

Uttar Pradesh, India

\section{Formulation and quality evaluation of turnip green (Brassica rapa) powder incorporated food products}

\author{
Tripathi Dipti and Yadav Latika
}

DOI: https://doi.org/10.22271/tpi.2021.v10.i4j.6030

\section{Abstract}

In present investigation efforts were made to prepare Turnip green powder by hot air oven drying method at $60^{\circ} \mathrm{C}$ for 5-6 hours. The prepared powder was used for the formulation of Chappati and Namakpara by using different proportions i.e., 5\%, 10\%, 15\%, 20\%, 25\% and 30\% with control. Six combinations were tried in each product with their control samples: T0, T1, T2, T3, T4, T5 and T6; by incorporating turnip green powder with other ingredients. The developed products were evaluated organoleptically by using nine point hedonic scales to select the best combination. Results showed that for all the treatments $15 \%$ turnip green powder was highly acceptable with a score for overall acceptability $8.81 \pm 0.03$ for Chapatti and $8.80 \pm 0.03$ for Namakpara. In conclusion substitution of wheat flour and refined flour with turnip green powder will be the good nutritional candidature for calcium and iron deficiency.

Keywords: turnip green powder, formulation, organoleptic, hedonic scales

\section{Introduction}

The dark-green leafy tops of the turnip plant (Brassica rapa) are known as turnip greens. In terms of vitamins, minerals, and health-promoting antioxidants, the greens have a higher nutritional profile than the tuber itself. Turnips are members of the Brassicacaea family and have the same standard growth characteristics as cabbage, kale, Brussel, sprouts, etc. The roots of Turnips can be grown in the temperate regions throughout the entire season. During winter, however, its top greens can be at their best. Turnip greens feature light green, large, long petiole leaves that rise directly from the top of the base. They taste similar to mustard greens, but with a spicy flavour that is less strong. Young tender greens have a sweet taste with a faint peppery undertone (www.nutrition- and- you.com). Turnip greens are filled with impressive quantities of antioxidants such as glucosinolate that help counteract many diseases. A glucosinolate is a large group of glucoside molecules containing sulphur which is well known for its ability to counteract cancer as it creates healthy cells and stimulates the death of cells within human cancer tumours. Turnip greens have two glucosinolates that are vital. It has ten times the amount of vitamin A as cabbage and ten times the amount of calcium as cauliflower. The leaves have high antioxidant content. According to research, a diet high in antioxidants can help prevent diseases like cancer, heart disease, diabetes, arthritis, Alzheimer's disease, autoimmune disease, and Parkinson's disease. These greens encourage immune function and lower the chances of free radicals causing oxidative stress (Health Benefits times.Com).

As they provide sufficient quantities of vitamins and minerals to humans, green leafy vegetables occupy a significant position among food crops. They are a rich source of vitamins such as $\beta$-carotene, ascorbic acid, folic acid, riboflavin, and calcium, iron and phosphorus minerals. There are many underutilised greens of promising nutritional value in nature that can feed a human population that is ever increasing. Many are climate-adaptive and tolerant. Although they can be raised even on poor marginal lands at lower management costs, due to a lack of awareness and popularisation of the use of technologies, they have remained underused. Underutilized foods are becoming increasingly important today as a means to increase the availability of percapita food (Joshi and Mathur, 2010). Being rich in nutrients, it is possible to use vegetable leaves to enrich inferior / deficient nutritional goods. Green leafy vegetables, according to Oguntona and Oguntona (1985), are an important part of the human diet. If not preserved within a few days of harvesting, these vegetables will begin to rot. Drying, one of the oldest methods of food preservation is commonly used to avoid these vegetables from rotting (Awogbemi et al., 2009).
Corresponding Author:

Yadav Latika

Assistant Professor,

Department of Food and

Nutrition, Faculty of Home

Science, Bindheswari P.G.

College, Akbarpur,

Uttar Pradesh, India

$$
\sim 653 \sim
$$


The present research study is therefore undertaken to formulate and evaluate value-added food product by incorporating turnip green (Brassica rapa) powder.

\section{Materials and Method}

Procurement of raw material: Turnip green leaves will be procured in a single lot form the local vegetable market of Akbarpur, Ambedkarnagar. All other raw materials mustard oil, wheat flour, salt, spices etc. were purchased from local market as and when required during the study.

\section{Preparation of Turnip green powder}

Collect the Turnip green fresh leaves, remove the stems and other unwanted parts. Wash the leaves with water to remove the dirt particles. Drain out excess water from leaves. Turnip green leaves were spread in a single layer in the hot air oven and dried at $60{ }^{\circ} \mathrm{C}$ for 5-6 hours (Constant weight was achieved in this time) till leaves became brittle and could be crushed easily when handled between fingers. The dried turnip green leaves were ground to fine powder milled by using mixer grinder. Turnip green powder (TGP) was stored in airtight container.

\section{Formulation of turnip green powder incorporated food products}

The turnip green powder incorporated traditional food products such as chappati and namakpara was prepared. Six combinations were tried for each food products and control sample was prepared from the standard recipes. The ingredients used for preparing each recipes and the formulation are presented in Table 1 and 2.

Table 1: Formulation of TGP incorporated Chapatti

\begin{tabular}{|c|c|c|c|c|c|c|c|}
\hline \multirow{2}{*}{ Ingredients (g) } & \multicolumn{7}{|c|}{ Treatments } \\
\cline { 2 - 8 } & Control & $\mathbf{T 1}$ & $\mathbf{T 2}$ & $\mathbf{T 3}$ & $\mathbf{T 4}$ & $\mathbf{T 5}$ & $\mathbf{T 6}$ \\
\hline Wheat flour & 100 & 95 & 90 & 85 & 80 & 75 & 70 \\
\hline Turnip green powder & - & 5 & 10 & 15 & 20 & 25 & 30 \\
\hline
\end{tabular}

Table 2: Formulation of TGP incorporated Namakpara

\begin{tabular}{|c|c|c|c|c|c|c|c|}
\hline \multirow{2}{*}{ Ingredients } & \multicolumn{7}{|c|}{ Treatments } \\
\cline { 2 - 8 } & Control & T1 & T2 & T3 & T4 & T5 & T6 \\
\hline Refined flour $(\mathrm{g})$ & 100 & 95 & 90 & 85 & 80 & 75 & 70 \\
\hline Turnip green powder (g) & - & 5 & 10 & 15 & 20 & 25 & 30 \\
\hline Ajwain seeds (gm) & 2 & 2 & 2 & 2 & 2 & 2 & 2 \\
\hline Salt (tsp) & $1 / 2$ & $1 / 2$ & $1 / 2$ & $1 / 2$ & $1 / 2$ & $1 / 2$ & $1 / 2$ \\
\hline Refined oil (ml) for frying & 150 & 150 & 150 & 150 & 150 & 150 & 150 \\
\hline
\end{tabular}

\section{Preparation of TGP incorporated Chappati}

Combine wheat flour, turnip green powder and salt together in a deep bowl and knead into soft dough using enough water. Cover the dough with muslin cloth and keep aside for 15 minutes. Divide the dough into equal proportions of small balls and roll out the balls into the round shape with rolling pin. Heat flat tawa on medium flame and place the chappati gently over it, cook it till small blisters appear on the surface, turn the chappati on other side and press all over chappati lightly using a muslin cloth till it puffs and cook properly from both sides.

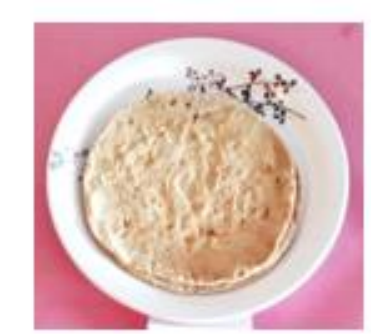

T0 (Control)

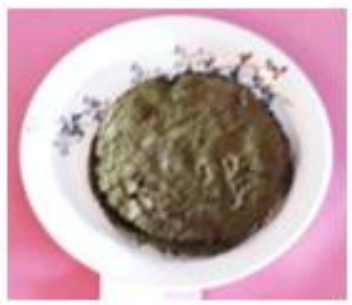

T4 (20\%)

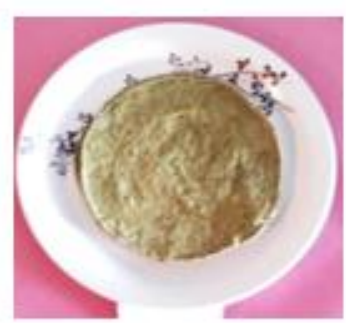

T1 (5\%)

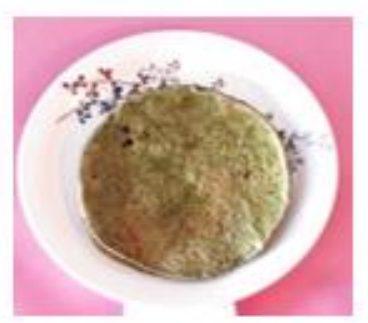

T2 $(10 \%)$

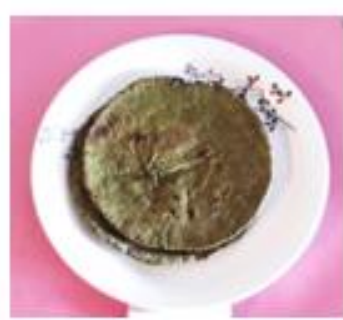

T3 (15\%)

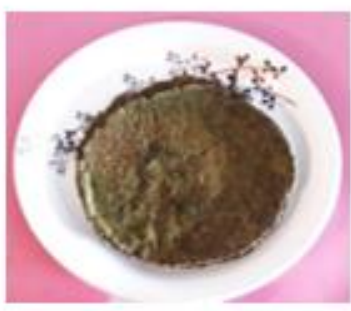

T5 (25\%)

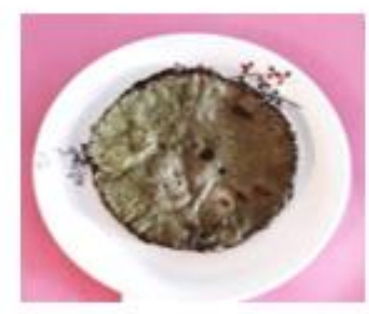

T6 (30\%)

Fig 2: Chappati prepared with different proportion of TGP

\section{Preparation of TGP incorporated Namakpara}

Refined flour, turnip green powder, ajwain seeds, salt and oil were mixed properly. Combinations of ingredients presented in Table 2. Knead hard dough with the help of luke warm water as required. It should be tighter than chapatti dough. Make small balls of dough and rolled into medium sized chapatti with rolling pin. Cut the chapatti into small diamond shapes. Heat the oil in a frying pan then deep fried till golden brown and crispy. Control namkpara was made without turnip green powder.

\section{Sensory Evaluation}

The prepared turnip green powder food products were organoleptically evaluated by ten panels of judges. For the selection of semi-trained panel members threshold test is used. The Chappati and Namakpara were evaluated for various sensory quality characteristics such as color, flavor, taste, texture, appearance, and overall acceptability. Evaluation of the chappati and Namakpara was done on the basis of 9 point hedonic scale. The test sample was given in triplicates with control. Control sample was prepared from the 
usual recipes. All samples were coded to avoid any type of biasness.

Table 3: Hedonic scale and scores for organoleptic evaluation

\begin{tabular}{|c|c|}
\hline Quality Description & Score \\
\hline Liked extremely & 9 \\
\hline Liked very much & 8 \\
\hline Liked moderately & 7 \\
\hline Liked slightly & 6 \\
\hline Neither like nor dislike & 5 \\
\hline Dislike slightly & 4 \\
\hline Dislike moderately & 3 \\
\hline Dislike very much & 2 \\
\hline Dislike extremely & 1 \\
\hline
\end{tabular}

\section{Nutritional composition of developed food products}

Nutritive value of GFFM was calculated by using Indian Food Composition Table (IFCT, 2017) published by National Institute of Nutrition (NIN).

\section{Statistical Analysis}

Statistically, all the collected data on organoleptic evaluation were analysed. Data were presented as mean \pm S.D. Analysis of Variance (ANOVA) was used to assess the sensory characteristics of developed food products. Statistical analysis was performed using O.P. STAT Software. Experiment was laid out in CRD (Completely Randomized Design) with three replications for each trial.

\section{Results and Discussion \\ Sensory quality of turnip green powder incorporating food products \\ Chapatti}

Chapatti are unleavened flat breads made from whole wheat flour and are served as the staple food in the Indian sub- continent Chapatti is one of the commonly consumed products in the lunch and dinner by adding turnip green powder in wheat flour, improve the nutritional quality of the product. Table 4 depicted the result of orgenoleptic evaluation of turnip green powder chapatti at different levels. Sensory scores reveal that the turnip green powder chapatti fell in the category of "liked very much" to "like moderately". Perusal of the sensory scores as evident from the Table 4 reveals that T3 (15\%) obtained highest scores i.e, $8.77 \pm 0.04$ for colour, $8.80 \pm 0.04$ for flavour, $8.72 \pm 0.04$ for texture, $8.82 \pm 0.02$ for taste, $8.82 \pm 0.02$ for appearance and $8.81 \pm 0.03$ for overall acceptability were compared to other counters parts. It is also clear that from overall acceptability point of view $\mathrm{T} 3(15 \%)$ scored the highest of $8.81 \pm 0.03$ and $8.57 \pm 0.10$ for $\mathrm{T} 1(5 \%)$, $7.25 \pm 0.09$ for $\mathrm{T} 4(20 \%), 7.22 \pm 0.013$ for $\mathrm{T} 5(25 \%), 8.19 \pm 0.04$ for $\mathrm{T} 2(10 \%)$ and $6.75 \pm 0.20$ for $\mathrm{T} 6(30 \%)$, respectively when compared to all other treatments and with control. On an overall acceptability basis it was found that $\mathrm{T} 3(8.81 \pm 0.03)$ scored the maximum followed by control $(8.55 \pm 0.03)$ and minimum score was obtained by T6 (30\%). The sensory scores obtained in case of turnip green powder chapatti depicted that on overall basis treatment T1 (15\%) was "liked very much". Similarly Sushmita et al., (2018) developed dehydrated mixture of green leafy vegetables (i.e., Amaranthus spinosus, Talinum triangulare and Chenopodium album) and incorporated in various products like roti, pakoda, fried nimke, baked nimke and salty biscuit. These greens were mixed in three different proportions and these formulations were computed for nutritional and tested for rehydration and found that Formulation- 1 was judged nutritionally superior and showed good physical properties after rehydration. Hence, Formulation 1 was incorporated in preparation of various recipes at $10 \%, 15 \%$ and $20 \%$ level and these were found acceptable upto $15 \%$ level of incorporation.

Table 4: Mean acceptability scores of TGP Incorporated Chapatti

\begin{tabular}{|c|c|c|c|c|c|c|}
\hline Treatments & Color & Flavor & Texture & Taste & Appearance & Overall Acceptability \\
\hline T0 (Control) & $8.72 \pm 0.02$ & $8.75 \pm 0.07$ & $8.35 \pm 0.02$ & $8.80 \pm 0.04$ & $8.60 \pm 0.09$ & $8.55 \pm 0.03$ \\
\hline T1 (5\%) & $8.82 \pm 0.33$ & $8.45 \pm 0.18$ & $8.12 \pm 0.02$ & $8.25 \pm 0.06$ & $8.62 \pm 0.39$ & $8.57 \pm 0.10$ \\
\hline T2 $(10 \%)$ & $8.17 \pm 0.10$ & $8.30 \pm 0.04$ & $8.22 \pm 0.04$ & $8.27 \pm 0.04$ & $8.20 \pm 0.07$ & $8.19 \pm 0.04$ \\
\hline T3 (15\%) & $8.77 \pm 0.04$ & $8.80 \pm 0.04$ & $8.72 \pm 0.04$ & $8.82 \pm 0.02$ & $8.82 \pm 0.02$ & $8.81 \pm 0.03$ \\
\hline T4 (20\%) & $7.25 \pm 0.06$ & $7.25 \pm 0.06$ & $7.20 \pm 0.09$ & $7.20 \pm 0.10$ & $7.25 \pm 0.06$ & $7.25 \pm 0.09$ \\
\hline T5 (25\%) & $7.25 \pm 0.13$ & $7.17 \pm 0.13$ & $7.15 \pm 0.08$ & $7.07 \pm 0.13$ & $7.20 \pm 0.10$ & $7.22 \pm 0.13$ \\
\hline T6 (30\%) & $6.97 \pm 0.13$ & $6.82 \pm 0.13$ & $7.17 \pm 0.13$ & $6.67 \pm 0.21$ & $6.95 \pm 0.06$ & $6.75 \pm 0.20$ \\
\hline
\end{tabular}

Values are expressed as mean \pm SD

\section{Namkpara}

Namakpara is one of the traditional Indian snacks made by the Refined flour and some amount of oil and spices. Namakpara also used as a snack with tea. Namakpara is a crunchy savoury snack eaten in India, Pakistan and Bangladesh. Namakpara is a ribbon like strips of pastry delicately seasoned with ajwain, cumin seeds and deep fried in pure ghee and refined oil. It requires approximately 10 minutes to prepare and 20 minutes to cook. Table 5 depicted the result of organoleptic evaluation of turnip green powder incorporated Namakpara at different levels. Sensory scores reveals that the turnip green powder Namakpara fell in the category of "liked very much" to " like moderately". Perusal of the sensory scores as evident from the Table 5 reveals that T3 (15\%) obtained highest scores i.e., $8.75 \pm 0.09$ for colour, $8.75 \pm 0.07$ for flavor, $8.77 \pm 0.04$ for texture, $8.75 \pm 0.09$ for taste, $8.87 \pm 0.63$ for appearance and $8.80 \pm 0.03$ for overall acceptability were compared to other counters parts. It is also clear that from overall acceptability point of view T3 (15\%) scored the highest of $8.80 \pm 0.03$ and $8.38 \pm 0.11$ for $\mathrm{T} 2(10 \%)$, $7.38 \pm 0.10$ for $\mathrm{T} 4(20 \%), 7.20 \pm 0.10$ for $\mathrm{T} 5(25 \%) 7.10 \pm 0.17$ for $\mathrm{T} 6(30 \%)$ and $8.42 \pm 0.06$ for $\mathrm{T} 1(5 \%)$, respectively when compared to all other treatments and with control. On an overall acceptability basis it was found that T3 (15\%) $8.80 \pm 0.03$ scored the maximum followed by Control $(8.57 \pm 0.03)$ and minimum score was obtained by T6 $(30 \%)$. The sensory scores obtained in case of Turnip green powder Namakpara depicted that on an overall basis treatment T1 (15\%) were "Liked very much". Similarly, Sharma et al., (2016) prepared a Nachos from oven dried turnip green powder and incorporated in different concentrations $10 \%$, $20 \%$ and $30 \%$ and found that test sample A (10\%) were highly acceptable as compared to control sample. 
Table 5: Mean acceptability scores of TGP incorporated Namakpara

\begin{tabular}{|c|c|c|c|c|c|c|}
\hline Treatments & Color & Flavor & Texture & Taste & Appearance & Overall Acceptability \\
\hline T0 (Control) & $8.72 \pm 0.02$ & $8.52 \pm 0.02$ & $8.32 \pm 0.02$ & $8.75 \pm 0.02$ & $8.52 \pm 0.09$ & $8.57 \pm 0.03$ \\
\hline T1 (5\%) & $8.95 \pm 0.25$ & $8.32 \pm 0.04$ & $8.35 \pm 0.06$ & $8.37 \pm 0.04$ & $8.37 \pm 0.04$ & $8.42 \pm 0.06$ \\
\hline T2 (10\%) & $8.95 \pm 0.30$ & $8.47 \pm 0.18$ & $8.40 \pm 0.04$ & $8.22 \pm 0.04$ & $8.22 \pm 0.04$ & $8.38 \pm 0.11$ \\
\hline T3 (15\%) & $8.75 \pm 0.09$ & $8.57 \pm 0.07$ & $8.77 \pm 0.04$ & $8.75 \pm 0.09$ & $8.87 \pm 0.63$ & $8.80 \pm 0.03$ \\
\hline T4 (20\%) & $8.00 \pm 0.17$ & $7.37 \pm 0.18$ & $7.25 \pm 0.20$ & $7.12 \pm 0.14$ & $7.45 \pm 0.13$ & $7.38 \pm 0.10$ \\
\hline T5 (25\%) & $7.62 \pm 0.08$ & $6.75 \pm 0.06$ & $7.17 \pm 0.04$ & $6.75 \pm 0.18$ & $7.30 \pm 0.05$ & $7.20 \pm 0.10$ \\
\hline T6 (30\%) & $7.60 \pm 0.14$ & $6.70 \pm 0.041$ & $7.10 \pm 0.15$ & $6.85 \pm 0.02$ & $6.85 \pm 0.02$ & $7.10 \pm 0.17$ \\
\hline
\end{tabular}

Values are expressed as mean \pm SD

\section{Nutrient composition of turnip green powder incorporated products}

Table 6 shows the nutrient composition of TGP and wheat flour chapatti. Control was discerned to contain protein 10 percent, fat 1.53 percent, ash 1.28 percent, fibre 11.36 percent, which was noted to be significantly higher than the TGP chapatti i.e., protein 9.58 percent, fat 1.52 percent, ash 1.41 percent and fiber 9.8 percent. But the carbohydrate content of the TGP chapatti 54.69 percent and energy 275.83 $\mathrm{Kcal} / 100 \mathrm{gm}$ was observed to be significantly lower than the Control (carbohydrate 64.17 percent and energy 312.73 $\mathrm{Kcal} / 100 \mathrm{gm})$. Whereas the calcium content of the TGP chapatti $132.79 \mathrm{mg} / 100 \mathrm{gm}$ and iron content $7.74 \mathrm{mg} / 100 \mathrm{gm}$. was observed to be significantly higher than the control (calcium 30.94mg/100gm and iron 4.10mg/100gm). The nutrient composition of TGP and refined flour Control was discerned to contain protein 10.36 percent, fibre 2.76 percent, which was noted to be significantly higher than the TGP namakpara i.e., protein 9.40 percent and fibre 2.49 percent. But the carbohydrate content of the TGP namakpara 64.53 percent and energy $303.60 \mathrm{Kcal} / 100 \mathrm{gm}$ was observed to be significantly lower than the Control (carbohydrate 74.27 percent and energy $345.36 \mathrm{Kcal} / 100 \mathrm{gm})$. Whereas the fat content of the TGP namakpara 0.86 percent, ash 0.76 percent, calcium $126.05 \mathrm{mg} / 100 \mathrm{gm}$ and iron content $27.21 \mathrm{mg} / 100 \mathrm{gm}$ was observed to be significantly higher than the Control (fat
0.76 percent, ash 0.51 percent, calcium $23 \mathrm{mg} / 100 \mathrm{gm}$ and iron $27 \mathrm{mg} / 100 \mathrm{gm})$.

Similarly Sushmita et al., (2018) incorporated dehydrated green leafy vegetables in snack items i.e. roti, nimkee, pakoda, salty biscuit and found high amount of micronutrients specially calcium and iron in products. Highest calcium content was found in greens incorporated pakoda (391.83 $\mathrm{mg} / 100 \mathrm{~g}$ ) followed by roti $(382.60 \mathrm{mg} / 100 \mathrm{~g})$, baked nimkee $(243.10 \mathrm{mg} / 100 \mathrm{~g})$, salty biscuit $(232.50 \mathrm{mg} / 100 \mathrm{~g})$ and fried nimkee $(225.80 \mathrm{mg} / 100 \mathrm{~g})$. The iron content of the products was in the range of $7.67-12.56 \mathrm{mg} / 100 \mathrm{~g}$. Per $10 \mathrm{~g}$ of Formulation 1 greens mixture provides $221.02 \mathrm{mg}$ calcium and $6.28 \mathrm{mg}$ iron, so by incorporating greens mixture in various proportion to common recipes, the calcium and iron content can be increased. Also Joshi and mathur (2013) prepared leaf mixture by mixing the less utilized leaves of beet root (Beta vulgaris), carrot (Daucus carota), cauliflower (Brassica oleracea) and turnip (Brassica rapa) powders in a definite ratio $(1: 2: 1: 1)$. Twenty different recipes with different levels $(0,5,10,15$ and $20 \%)$ of leaf mixture were prepared and found that the products were well accepted to the level of $10 \%$. Protein, iron and calcium content were significantly $(\mathrm{p}<$ 0.05 ) higher in the LM incorporated recipes and the increase was directly proportional to the level of leaf mixture incorporated.

Table 6: Nutrient composition of turnip green powder incorporated food products

\begin{tabular}{|c|c|c|c|c|}
\hline $\begin{array}{c}\text { Nutrient } \\
\text { constituents }\end{array}$ & $\begin{array}{c}\text { Control } \\
\text { Chapatti }\end{array}$ & $\begin{array}{c}\text { TGP (T3) } \\
\text { Chapatti }\end{array}$ & $\begin{array}{c}\text { Control } \\
\text { Namakpara }\end{array}$ & $\begin{array}{c}\text { TGP (T3) } \\
\text { Namakpara }\end{array}$ \\
\hline Protein(g) & 10.57 & 9.58 & 10.36 & 9.40 \\
\hline Fat(g) & 1.53 & 1.52 & 0.76 & 0.86 \\
\hline Ash(g) & 1.28 & 1.41 & 0.51 & 0.76 \\
\hline Fibre(g) & 11.36 & 9.8 & 2.76 & 2.49 \\
\hline Carbohydrate(g) & 64.17 & 54.69 & 74.27 & 64.53 \\
\hline Energy(Kcal) & 312.13 & 275.83 & 345.36 & 303.60 \\
\hline Calcium(mg) & 30.94 & 132.79 & 23 & 126.05 \\
\hline Iron(mg) & 4.10 & 7.74 & 27 & 27.21 \\
\hline
\end{tabular}

* Values are expressed from 100gm of edible portion

\section{Conclusion}

Dehydration is one of the best green leafy vegetable preservation methods. As a consequence of the dehydration, they become a concentrated source of vitamins and minerals, making them an outstanding "natural fortifier." These GLVs can be stored to reduce waste and make them usable during the off season. Green leafy vegetables can be used to enrich nutritionally deficient products because they are high in micro nutrients. For value-added products, dehydrated green leafy vegetable powder should be used in many traditional and commercial products to resolve health-related problems. Dehydrated vegetables are easy to use and have a longer shelf life than fresh vegetables, in addition to waste reduction. The protein content of dehydrated GLVs is equivalent to that of legumes.

\section{Reference}

1. http://www.Nutrition-and-you.com. 27 February 2021.

2. https://www.healthbenefitstimes.com/turnip-greens. 27 February 2021.

3. Awogbemi, Omojola, Ogunleye I. Olusola. Effects of drying on the qualities of some selected vegetables. International Journal of Engineering and Technology 2009;1:5.

4. Joshi P. and Mathur B. Preparation of value added products from the leaf powders of dehydrated less utilized green leafy vegetables. Journal of horticulture and forestry 2010;2(9):223-228. 
5. Oguntona T, Oguntona CRB. Proximate Composition of three leafy vegetables Commonly in North-eastern Nigeria. M.Sc (Biochemistry) Thesis, University of Ibadan, Nigeria. 1985 (Unpublished) 1985.

6. Sharma Priyanka, Thukral Bhavna, Sharma Mahak. Development of a product rich in calcium prepared turnip green powder. Indian Journal of Applied Research 2016;6(7):144-145.

7. Sushmita Khatoniar, Mridula Saikia Barooah, Mamoni Das. Formulation and Evaluation of Dehydrated Greens Incorporated Value Added Products. Int. J Curr. Microbiol. App. Sci 2018;7(06):94-102. 